\title{
Effect of Organizational Change on Employee Job Performance
}

\author{
Cross Ogohi Daniel \\ Department Of Public Administration/ Banking and finance \\ Nile University Of Nigeria, Abuja \\ Email: danielcross [AT] nileuniversity.edu.ng
}

\begin{abstract}
As businesses evolve, to keep ahead of competition, so do their expectations for their employee's performance. An employee is a key element of an organization and their overall performance can decide the achievements of an organization or its failures. Every business has their own specific way of doing things, due to the constant change of the business environment. This changes therefore requires organization to adopt internal changes which tends to affect the performance of employees thus may enhance organisational growth and otherwise. The general objective of this research is to evaluate the effect of organizational change on employee job performance and compare it with the transformation framework articulated by some change management theorist and also to explore whether organizational change affect the job performance of employees. This study will make use of the data that was analyzed using the content analysis approach. This is because of its major dependence on the secondary source data. The result of the evaluation will provide how organisational change can be improved. There are some reasons why it is important that an organization must always affect a change process. The organization must consider that employees are very vital in carrying out a change process. Sustainable long-term success and performance of the organization depends on employees.
\end{abstract}

Keywords---- Organisational Change, Employees’ Performance, Organisational Structure, Strategy and System

\section{INTRODUCTION}

Organizations are compelled to implement changes as a way of remaining competitive through adaptation to the ever changing business environment (Balogun \& Hailey, 2008). Researchers have provided evidence to the effect that many change processes fail to achieve the intended objectives.

Meaney and Pung (2008) estimated the failure rate to be in the region of 60\%. Some researchers such as Ford (2008) have listed employee resistance to change as one of the important reasons why organization fails to implement change successfully. One of the renowned researchers on managing change is Kurt Lewin (1951) who provided a theoretical framework which managers can adopt when implementing change processing which employee resistance would be minimized.

According to Spector (2013), Lewin's theory is based on three phases of transformation. The author named the first phase as the unfreezing. Unfreezing centers around the need to remove the convictions and presumptions of the individuals who need to participate in systematic modifications to the status quo. It can along these lines be said that Unfreezing alludes to the creation of a perceived error between the current and ideal state of an organization that creates a craving for change and brings down individuals protection from change (Lewin, 1951).

Amid the time of unfreezing, those who are fixed in the systems or its frameworks become helpless to Change. The second stage is the change or moving stage which refers to the various processes such as training, education, and restructuring that lead to the development of new behaviors, attitudes, and beliefs. Systems and structures, beliefs and habits become fluid and this can shift more easily. Upon the completion of the Change stage, these systems, structures, beliefs and habits can refreeze in their new form. The final stage is the refreezing stage. During this stage, a new state of equilibrium within the organization is established by stabilizing the new patterns through a variety of support mechanisms.

According to Lewin (1951), for permanent change to be achieved, new structures and roles are needed and new points of balance or homeostasis are developed. The author explained that employee resistance during the freezing stage can be attributed to entrenched culture, norms and beliefs which discourage employees from adapting new processes of conducting work.

Any employee attempting to conduct work using a new system which is in conflict with entrenched norms, beliefs and culture is forced by peers to abandon the new procedures due to severe pressures from peers. If the resistance is not properly addressed, it can continue to manifest in the later stages of transformation thereby, posing a risk to the achievement of the 
change objectives. The implication of this employee resistance to change is that managers have to take cognizance of the importance of employees' commitment to the change process as a way of addressing potential resistance.

The purpose of this research is to evaluate the effect of organizational change on employees' performance as a way of assessing whether additional strategy measures are required to ensure successful implementation of the change process.

\section{STATEMENT OF THE PROBLEM}

These days, because of the fierce competitive environment fast changes happened in the organizations which expanded the competition for gaining revenues and growth. The perception of organizational change interests mainly with the organizational wide transformation, which mainly include the changes in term of mission of the organization, operations of the organization, mergers, major partnerships etc.

There are researchers who say that organizational change means organization transformation. In order to rehearse quality standard, value is vitally important and it sets the genuine convictions so as to accomplish performances in teams and to deliver the superior customer service to the clients. At the point when change begins to appear then leaders get the opportunity to lead their workforce in better perspectives. However, employee's obligation is essential in order to move the organization towards growth and progress.

\section{OBJECTIVES OF THE STUDY}

The general objective of this research is to evaluate the Effect Of Organizational Change On Employee Job Performance and compare it with the transformation framework articulated by some change management theorist and also to explore whether organizational change affect the job performance of employees

i. To Identify the Organizational change process adopted by management

ii. To Determine if the Organizational change influences employee job performance

\section{LITERATURE REVIEW}

\subsection{Conceptual framework on organisational change}

The conceptualization of change predominated from nature and environment of an organisation. According to Kassim, (2010), change is a series of events that systematically supports organization development process. This process generally means rightsizing or downsizing, new development and technological change, operations repositioning and major partnerships (McNamara, C., 2010).

\subsection{Types of change}

Kotter categorized the process of change management into three: business process re-engineering, technological change, and incremental change.

Business process re-Engineering: Business process re-engineering is a process of implementing change in a firm by which the old methods of doing things is completely turn down for a more meaningful change implementation. This process helps companies to drastically restructure an organization as it focuses on the business of the organization from top-down.

Incremental change: This process does not really alter the current structure of an organization but make a small adjustment by focusing on the end result. It is a step by step process to improve overall process efficiency.

Technological change: This is a process whereby an organization embraces invention, innovation and diffusion of processes for operational efficiency. In order words, technological change is an integration of technology into organization processes.

\subsection{Reasons for change}

Gareth (2017) gave four reasons why an organizational change is important.

1. To deal with contingencies - contingencies are possible events that may arise in the course of time and must be planned for. Most of these unforeseen events come from the external environment. It is therefore imperative for every organization to be designed in such a way that such unforeseen environmental changes will be effectively responded to.

2. To manage diversity - according to Jones (2017) ${ }^{[8]}$, differences in race, gender and national origin of organization members plays an important implication where organization culture and effectiveness is concerned. It is therefore important to learn how to effectively utilize a diversified workforce who can result in better decision making and more effective workforce.

3. To gain competitive advantage - it is important for every organization to set aright the ability to outperform other companies. This is to ensure the capacity to create more value from resources. In achieving this therefore, there are two key elements that must be put in place' 
Core-competencies - these are skills and abilities in value creation embedded in the organization's people or structures.

Strategy - this is a pattern of decision and actions involving core competencies that produces a competitive advantage to outperform competitors.

To promote efficiency, speed and innovation - it goes without saying that the better organization function, the more value they create. This simply means that when an organization change is rightly implemented, it may lead to faster and speedy innovation thereby increase efficiency.

\subsection{Managing change process}

Different theories proposed ways for managing change process in an organization. Lewin (1951) stated that critical aspect of organizational change as a company's ability to win the buy-in of employees on the intended change process. He further identified a four step process for managing a change process which includes; recognizing the changes across business environment; developing necessary adjustments for organizational needs; training employees on appropriate change needed; and gaining the support of employees.

He explained that organizational change management process should start with a systematic diagnosis of the present situation within the company in order to determine both need for change and capability of the organization to change.

According to Lewin (1951) change management process should include communication between key audiences or stakeholders and understanding of leadership style and group dynamics plays another important element in the change management process.

The general objective of a change management process is to align group's expectations, integrate teams and manage employees training in order to make use of performance metrics such as the outcome of financial results, operational viability and effectiveness, responsibility, correspondence and avoid change failures.

\subsection{Problems of change management}

Change management is faced with the fundamental difficulties of integration and navigation, and human factors. Change management must also consider the human angle where feelings and how they are dealt with plays a huge role in actualizing change successfully.

Integration: Traditionally, organizational development (OD) departments neglected the role of infrastructure and the likelihood of carrying out change through technology. Now, managers almost exclusively focus on the structural and technical components of change. Arranging and coordinating the vital, social, and specialized segments requires joint efforts between people with various range of skill-sets.

Navigation: Managing change over time, referred to as navigation, requires continuous adaptation. It requires overseeing projects over time against a changing context, from inter-organizational factors to marketplace volatility. It also requires a parity in bureaucratic organizations between top-down and bottom-up management, ensuring employee empowerment and flexibility.

Human factors: One of the major factors which hinder the change management process is people's natural tendency for inertia. Just as in Newton's first law of motion, people are resistant to change in organisations because it can be uncomfortable. The notion of doing things this way, because 'this is the way we have always done them', can be particularly hard to overcome. Furthermore, in situations where an Organization has seen declining fortunes, for an official or manager to view them as a key piece of the issue can be exceptionally lowering. This issue can be exacerbated in countries where "saving face" assumes a vast role in inter-personal relations.

\subsection{Targets of organizational change}

Gareth (2017) stated that targets of change include improving effectiveness at four different levels.

1. Human Resources Level - typical kinds of organization change efforts directed at Human Resources includes; intense investment in training and development of employees; socializing and connecting with representatives into the organization culture; changing organization standards and qualities to motivate a multicultural and diverse workforce; advancement and reward frameworks and changing the structure of the top management team.

2. Functional Resources Level - Jones mentioned that change efforts by transferring resources to the functions where the most value can be created in response to environment change are important. He further states that an organization can improve the value that its functions create by changing its structure, culture and technology.

3. Technological Capabilities Level - change endeavors directed at technological capabilities are expected to give an organization the capacity to change itself in order to exploit market opportunities. Jones further stressed that technological capabilities are core competence as far as change target is concerned. 
4. Organizational Capabilities - change efforts directed at organization capabilities alter organization culture and structure, thereby permitting the organization to harness its human and functional resources to exploit technological opportunities.

\subsection{Resistance to change}

Gareth (2017) explained that one of the main reasons for some organizations' inability to change is organization inertia that maintains the status quo. According to him, resistance to change lowers an organization's effectiveness and it reduces its chances of survival. He identified levels of resistance to change firstly, organizational level resistance to change which stems from; power and conflicts as a result of power struggle and conflicts; differences in functional orientation; mechanistic structure; and organization culture. Secondly, group-level resistance to change which stem from; group norms; group cohesiveness; group think; and escalation of commitment. Finally, individual level resistance is amount to change which stems from; uncertainty and insecurity; selective perception and retention and habit.

\subsection{Employee performance}

Employee performance is fundamental for the achievement of each organization and profitability in this dynamic environment (Chien, 2004) ${ }^{[9]}$. These days, organizations require such sort of employees who put in more than their job scope and far from goals expectations. The vast majority of the organizations copping with contemporary difficulties put more accentuation on performance of the employee (Gruman and Saks, 2011) ${ }^{[10]}$. According to some authors, service firms invests more on their work force in order to maintain long term relationship with them and to increase their performance along with job satisfaction (Gruman \& Saks, 2011) ${ }^{[10]}$. Downsizing, mergers, innovations and restructuring of the organizations usually decrease employee's performance. In additions to that, task, quantity and quality, changing location and time constraints radically affect the work life of employees (Tavakolia, 2010) ${ }^{[11]}$. These days, many firms are facing current difficulties and need to force more concentration on elevating employees' performance. More so, to connect in worthy performance, managers need to let employees to have more power to design their jobs and roles. In this way, employees will discover their jobs more fit between employees' needs, skills and values (Gruman \& Saks 2011) ${ }^{[10]}$. The deficiencies of employee performance will be overcome by effective leadership, communication, motivation, employee development, self-directed teams, and organizational culture.

\section{THEORETICAL REVIEW}

The theoretical framework introduces and describes the theories that explain why the research problem under this study exists. The various models and approaches to change management process in an organization are important as it gives guidelines on implementation of change management in an organization. Categorically, we can say change implementation falls into three types: Top-down change management - this by definition is based on the assumption that if change agents plan things well, change can be effectively and smoothly executed. According to theorist, obstacles may arise from employees' resistance; hence the focus is on changing culture in an organization. Transformational change management focuses on transformational leaders by setting the pace and encouraging people to be innovative while providing grounds for work safety environment. Strategic change management is in contrast with the top-down models as it introduces new behaviors at work and involves employees in the change process as a whole.

\subsection{The emergent approach to organizational change - Kotter's model of change}

This approach model is a response to criticisms leveled against the planned model of change. The emergent approach is also known as continuous improvement or organizational learning (Burnes, 2004). According to (Burnes, 2004)., the emergent approach sees change as a procedure driven from bottom-up instead of top-down and further emphasizes that change is an open-ended and continuous process of adaptation to changing conditions and circumstances. The emergent approach to change also stated the need for change not to be perceived as a series of linear events within a given period of time rather should be perceived as a continuous, open-ended process of adaptation to changing circumstances and conditions (Burnes, 2004)

According to (Burnes, 2004)., the emergent approach promotes 'extensive and in-depth understanding of strategy, structure, systems, staff, style and shared values and how these can function either as sources of inertia that can block change, or alternatively, as levers to encourage an effective change process. Further to this, the success of change management should be less dependent on detailed plans and change initiatives. In rather stated that emphasis should be on reaching an understanding the complexity of the issues concerned with the change and identifying the range of available options.

In other words (Burnes, 2004) connoted that this approach should focus more on change readiness and the means of facilitating the proposed change process and make a specific pre-planned process for each change initiative secondary. In addition to the emergent approach to change, Kotter (1996) identified sequences of actions that organisations can adopt. His eight steps suggestions in change process are; initiating a sense of urgency; creating the guiding coalition; developing a vision and strategy; imparting the change vision; engaging employees for broad based action; generating short term wins; combining gains and delivering more change; and anchoring new approaches in the culture. 


\subsection{The transformational approach to change management}

The challenge behind organisational change are numerous and in various ways. Changes occur in the national economy, customer needs and wants and government laws and regulations guiding tariffs and order and basically the competitive environment. All these have put the power sector as a whole under pressure and thus the need to change both internally and externally its operations and management systems becomes so imperative.

The challenged generally faced by the power sector led to the transformation of the power sector in Nigeria and has also forced the Nigerian Power Sector to re-think and re-design their jobs to reduce costs and increase productivity and efficiency. An organization cannot survive in competitive environments if it does not design and promote services that satisfy changing customer preferences and market conditions. In addition, technical invention in organisations has led to improvements in productivity efficiency and market competitiveness.

In addition to this, transformational change is time-consuming and requires good coordination efforts and solid management support. All the observation postulated on transformational change demonstrate more dimensions of the issue, which are useful in helping to visualize the impact upon organisational strategies, new behaviour sets, modified organisational culture and the renewal of organisational processes, especially in government sector agencies.

\section{METHODOLOGY}

The paper adopted a singular source of data collection. The secondary source of data generation, which include the use of textbooks written by different authors on the subject matter, journals, magazines, information from the internet and other published and unpublished materials relevant to work. The data was analyzed using the content analysis approach. This is because of its major dependence on the secondary source data.

\section{CONCLUSION}

The objective of this paper has been achieved. The change process at Nigerian Companies has been reviewed.

Recommendations on how this process can be made more effective have been made by leveraging on change management process theory by Mckinsey and other researchers. Various aspects of the change process at Nigerian companies have been analysed and appropriate interventions and techniques have been presented in a logical sequence order to maximise opportunities for success. The conclusions are therefore based on the investigation on how organisational change process can affect employee job performance. In addition, the research work can be used as reference material to various leaders in the other organisations in order to lead the transformation process according to the change management theory, thereby maximizing their chances of success.

\section{RECOMMENDATIONS}

There are some reasons why it is important that an organisation must always affect a change process. The organization must consider that employees are very vital in carrying out a change process. Sustainable long-term success and performance of the organization depends on employees.

Following are the points for recommendations with respect to this study.

1. Management must ensure the full implementation of Human Resources Management policy in organization and ensure the use by all employees

2. Management should cultivate the habit of engaging their employees in the implementation process of change and improvement of Human Resources Management's policy organizational wide.

3. Management should incorporate a training schedule and employee development program for general staff on the implementation of change and the newly developed HRM policy. This is to ensure employees are in the know and get familiar with the change process.

4. The process of communication and the system of communication must be well aligned in order to avoid rumors that could negatively influence the successful implementation of change process in an organization.

5. An evaluation should be conducted evaluations on employee performance in order to give room for promotions and rewards based on merit.

6. This study finally recommends for the management to put in place good change management monitoring and feedback process in order to fully achieve its objectives.

\section{REFERENCES}

[1] Balogun, J. and Hope Hailey, V. (2008), Exploring Strategic Change, Prentice Hall, London.

[2] Meaney, M. and Pung, C. (2008), "McKinsey global results: creating organizational transformations", The McKinsey Quarterly, August, 2008, pp. 1-7. 
[3] Ford, J.D., Ford, L.W. and D'Amelio, A. (2008), "Resistance to change: the rest of the story", Academy of Management Review, Vol. 33 No. 2, pp. 362-77.

[4] Lewin, K. (1951).Field Theory in Social Science: Selected Theoretical Papers by Kurt Lewin, Ed. Dorwin Cartwright, Boston, Massachusetts: MIT Research Center

[5] Spector, B. (2013). Implementing organizational change: Theory into practice. Boston: Pearson.

[6] Kassim, A. W., Tahajuddin, S. B., Shahzad, A., Isa, E. V., \& Mat, N. (2010). Preliminary insights into the role of space in organizational change. The Journal of International Management Studies, 5(2), 50-58.

[7] McNamara, C. (2011, April 20). Organizational change and development (Managing change)

[8] Gareth R. Jones (2017) Socialization Tactics, Self-Efficacy, and Newcomers' Adjustments to Organization. Academy of Management Journal, 29 (2), 54-65

[9] Chien, M. H. (2004). An investigation of the relationship of organizational structure, employee's personality and organizational citizenship behaviors. Journal of American of Business, 5 (1/2), 428-431.

[10] Gruman, J. A., \& Saks, A. M. (2011). Performance management and employee. Human Resource Management Review, 21 (2), 123-136.

[11] Tavakolia, M. (2010). A positive approach to stress, resistance, and organizational. Social and Behavioral Sciences, 5, 1794-1798.

[12] Burnes, B. (2004). Managing change; a strategic approach of organizational dynamic. Fourth Edition. England. Prentice Hall, New Jersey

[13] Burnes, B.A. (2004). Kurt Lewin and complexity theories: back to the future? Journal of Change Management, 4(4), 309-325.

[14] Kotter, J. (1996). Leading Change: Why Transformation Efforts Fail. Harvard Business Review, New Jersey 